\title{
Ring-shear studies of till deformation: Coulomb-plastic behavior and distributed strain in glacier beds
}

\author{
Neal R. Iverson, ${ }^{1}$ Thomas S. Hooyer, ${ }^{1}$ Robert W. Baker ${ }^{2}$ \\ ${ }^{1}$ Department of Geological and Atmospheric Sciences, Iowa State University, Ames, Iowa 50011, U.S.A. \\ ${ }^{2}$ Department of Plant and Earth Science, University of Wisconsin-River Falls, River Falls, Wisconsin 54022, U.S.A.
}

\begin{abstract}
A ring-shear device was used to study the factors that control the ultimate (steady) strength of till at high shear strains. Tests at a steady strain rate and at different stresses normal to the shearing direction yielded ultimate friction angles of $26.3^{\circ}$ and $18.6^{\circ}$ for tills containing $4 \%$ and $30 \%$ clay-sized particles, respectively. Other tests at steady normal stresses and variable shear-strain rates indicated a tendency for both tills to weaken slightly with increasing strain rate. This weakening may be due to small increases in till porosity.

These results provide no evidence of viscous behavior and suggest that a Coulombplastic idealization is reasonable for till deformation. However, viscous behavior has often been suggested on the basis of distributed shear strain observed in subglacial till. We hypothesize that deformation may become distributed in till that is deformed cyclically in response to fluctuations in basal water pressure. During a deformation event, transient dilation of discrete shear zones should cause a reduction in internal pore-water pressure that should strengthen these zones relative to the surrounding till, a process called dilatant hardening. Consequent changes in shear-zone position, when integrated over time, may yield the observed distributed strain.
\end{abstract}

\section{INTRODUCTION}

Since the provocative geophysical work on Ice Stream B, Antarctica (Blankenship and others, 1986), which suggested that fast flow of the ice stream might be facilitated by pervasive deformation of the underlying till (Alley and others, 1986), there have been many studies aimed at modelling the flow of modern and past glaciers on deformable beds (e.g. Boulton and Hindmarsh, 1987; Clarke, 1987; Alley, 1989; MacAyeal, 1989; Kamb, 1991; Jenson and others, 1996). Some studies have focused on sediment transport in deforming beds (Alley, 1991; Boulton, 1996; Hooke and Elverhøi, 1996), and some models have emphasized that such transport may be an important factor in controlling the long-term stability of ice sheets (e.g. MacAyeal, 1992). Other analyses have focused on ploughing, a process that may concentrate strain in till near clasts at the bed surface (Brown and others, 1987; Alley, 1989). Others interested in subglacial hydrology have analyzed deformation of till adjacent to subglacial conduits (Boulton and Hindmarsh, 1987; Alley, 1992; Walder and Fowler, 1994).

Despite these efforts, the role of bed deformation in glacier dynamics and sediment transport remains obscure. More than any other single factor, this uncertainty stems from a lack of definitive laboratory and field data that bear on the rheology of till. Models, therefore, have sometimes been built on grossly different rheological assumptions with frequently divergent results.

In this paper, the results of laboratory experiments with a ring-shear device are reported. They indicate that two tills with different clay contents behave as essentially Coulomb(frictional-)plastic materials. In contrast, the distributed shear strain that has sometimes been observed in till beneath modern glaciers has been taken to be indicative of viscous behavior. We suggest, as one working hypothesis, that distributed deformation may arise in cyclically deformed till as a consequence of dilatant hardening, in which a dilating shear zone is strengthened by a consequent reduction in pore-water pressure.

\section{BACKGROUND}

If sheared to a sufficiently large strain, sediment will deform at a steady porosity and shear stress and is said to be in the "critical state". The shear stress in the critical state is referred to as the ultimate or residual strength. As noted by Kamb (1991) and by Hooke and others (1997), of fundamental concern is the relation between this strength and the rate of deformation. Differences of opinion regarding the form of this relation have led authors to advocate disparate constitutive relations for till deformation. These can be grouped as either Coulomb-plastic or viscous relations.

\section{Coulomb-plastic behavior}

If sediment deforms as a Coulomb-plastic material, then the ultimate strength depends linearly on the effective pressure, $P_{\mathrm{e}}$, and is independent of the strain rate, such that $\tau=P_{\mathrm{e}} \tan \phi_{\mathrm{u}}$, where $\phi_{\mathrm{u}}$ is the ultimate friction angle. Cohesion, in principle, is absent in the critical state (Lambe and Whitman, 1979, p. 312). Laboratory experiments on till and other fine-grained sediment usually indicate either a weakening or a strengthening with increasing strain rate, but the change is sufficiently small tojustify the plastic ideal- 
ization. Tika and others (1996) presented the results of ringshear tests on a variety of sediment, including till, which indicated only a $10 \%$ variation in ultimate strength over strain rates that were varied through four orders of magnitude. Only at rates of shearing displacement considerably larger than those expected subglacially were rate effects, both positive and negative, significant. Kamb (1991) tested sediment collected from beneath Ice Stream B and found that the rate of shearing did not affect the shear strength, although it is unclear in these tests whether the ultimate strength was reached. Some data indicate a small systematic increase in ultimate strength with strain rate of the form:

$$
\frac{\tau_{\mathrm{u}}}{\tau_{0}}=1+b \ln \left(\frac{\dot{\epsilon}}{\dot{\epsilon}_{0}}\right) \quad \dot{\epsilon}>\dot{\epsilon}_{0}
$$

where $\dot{\epsilon}$ is the strain rate, and $\tau_{0}$ is a reference stress at a reference strain rate, $\dot{\epsilon}_{0}$ (e.g. Mitchell, 1993, p. 343). As noted by Kamb (1991) and by Hooke and others (1997), the constant $b$ in this relation is small, about 0.015 for fine-grained sediment sheared at glacial rates (Skempton, 1985). Thus, since $\tau_{0}$ should depend linearly on $P_{\mathrm{e}}$ (Kamb, 1991; Hooke and others, 1997), Equation (1) does not depart significantly from the Coulomb-plastic idealization.

Some field measurements also suggest a Coulomb-plastic rheology (Hooke and others, 1997). The force on dragometers (Iverson and others, 1994) and ploughmeters (Fischer and Clarke, 1994) as they were pulled through till beneath Storglaciären (Sweden) varied directly with the effective pressure, as is expected of a Coulomb material. But the force did not vary systematically with the rate at which the instruments were inferred to be drawn through the till. This implied that the ultimate strength was insensitive to the strain rate induced in the till adjacent to the instruments, consistent with plastic behavior.

\section{Viscous behavior}

The constitutive relation for till deformation that has had the greatest influence on subsequent work stems from the field study of Boulton and Hindmarsh (1987), who suggested a relation of the form:

$$
\dot{\epsilon} \propto \frac{\left(\tau-\tau_{\mathrm{c}}\right)^{n}}{P_{\mathrm{e}}^{m}},
$$

where $\tau$ is the shear stress, $n$ and $m$ are empirical constants, and $\tau_{\mathrm{c}}$ is a critical stress below which there is no permanent deformation. The value of $\tau_{\mathrm{c}}$ is usually taken to be the MohrCoulomb yield strength, which varies linearly with $P_{\mathrm{e}}$. From a fit to field measurements of bed shear-strain rates, porewater pressures and shear stresses beneath the terminus of Breidamerkurjökull, Iceland, values of $m$ and $n$ close to 1.0 were determined. Thus, it was suggested that the till behaved as a linear or mildly non-linear Bingham viscous fluid. However, as argued previously (Hooke and others, 1997; Iverson and others, 1997), the lack of explanation for how shear stresses were measured in the study, and the likelihood that shear stresses were dominated by longitudinal stress gradients, which were apparently not taken into consideration, make these results difficult to interpret.

Some data from laboratory tests on till have also been interpreted to reflect a relation between strain rate and stress that is only mildly non-linear. Ho and others (1996) describe results from direct simple shear tests on finegrained till conducted at constant stresses and conclude that a stress exponent of $1.32-3.08$ is suggested by their data. A problem in interpreting the results of these tests, however, is that steady strain rates were not achieved at a given stress. Indeed, data from these tests (Vela, 1994) indicate that strain rates were still decreasing when a new larger stress was applied.

Observations that shear strain is sometimes distributed across a significant thickness of a basal till layer Boulton and Hindmarsh, 1987; Blake and others, 1992; Humphrey and others, 1993) have sometimes been invoked as evidence for viscous behavior. Similarly, shear strain at the bases of non-inertial landslides, comprised of sediment similar to till, is often distributed across $1 \mathrm{~m}$ or more of sediment (Savage and Cheleborad, 1982; Iverson, 1986). When measured velocity profiles in slow landslides, for example, are fit to constitutive relations of the form of Equation (2) with $m=0$, strain is distributed sufficiently that values of $n$ of 1.0-5.0 are implied (Savage and Cheleborad, 1982: $n=1.0$; Iverson, 1986: $1.0<n<5.0$ ). Thus, although such distributed deformation in no way demonstrates viscous behavior, it is consistent with a viscous rheology.

In contrast, continuum models of Coulomb plasticity, laboratory experiments and distinct-element models that make no continuum assumption indicate that under most boundary conditions shear strain should tend to localize in granular materials undergoing steady deformation, particularly at high strains. Such localization is due to both stress gradients and mechanical heterogeneity. Although there are numerous plasticity models with guiding assumptions that differ markedly, the most successful for granular materials is so-called non-associated plasticity (e.g. Gerbault and others, 1998). This model takes into account particle friction, the lack of volume change in the critical state, and the non-coaxiality of stress and strain rate in granular materials. It predicts that plastic strain should tend to focus in narrow zones, surrounded by sediment undergoing only elastic strain. It is well supported by a variety of laboratory experiments, including the pioneering ring-shear tests of Mandl and others (1977) and biaxial tests (Vardoulakis, 1980; Vardoulakis and Graf, 1985). Distinct element models (Cundall and Strack, 1979), which generate bulk behavior by considering only the physics of particle contacts, reinforce this viewpoint. In two-dimensional shear simulations with a mixture of grain-sizes and no pore fluid, Morgan and Boettcher (in press) found with such a model that deformation became focused in a thin zone parallel to the shearing direction, similar to that observed in ring-shear tests (Mandl and others, 1977; Dewhurst and others, 1996; Iverson and others, 1996). The strain localization was due to the mechanical segregation of small grains, which supported small forces, rotated easily, and therefore acted as low-friction bearings between large particles.

\section{APPARATUS}

A ring-shear device (e.g. Bishop and others, 1971) was constructed to study the mechanical properties of till at high strains (Fig. 1). Other, more detailed descriptions of the device have been presented elsewhere (Iverson and others, 1996, 1997). The device shears a remolded confined till specimen between horizontal parallel plates. The specimen, 60$75 \mathrm{~mm}$ in thickness, occupies a chamber that has an outside diameter of $0.6 \mathrm{~m}$ and a width of $0.115 \mathrm{~m}$. An internal reservoir contains water that is open to the atmosphere and in 


\section{Ring-shear device}

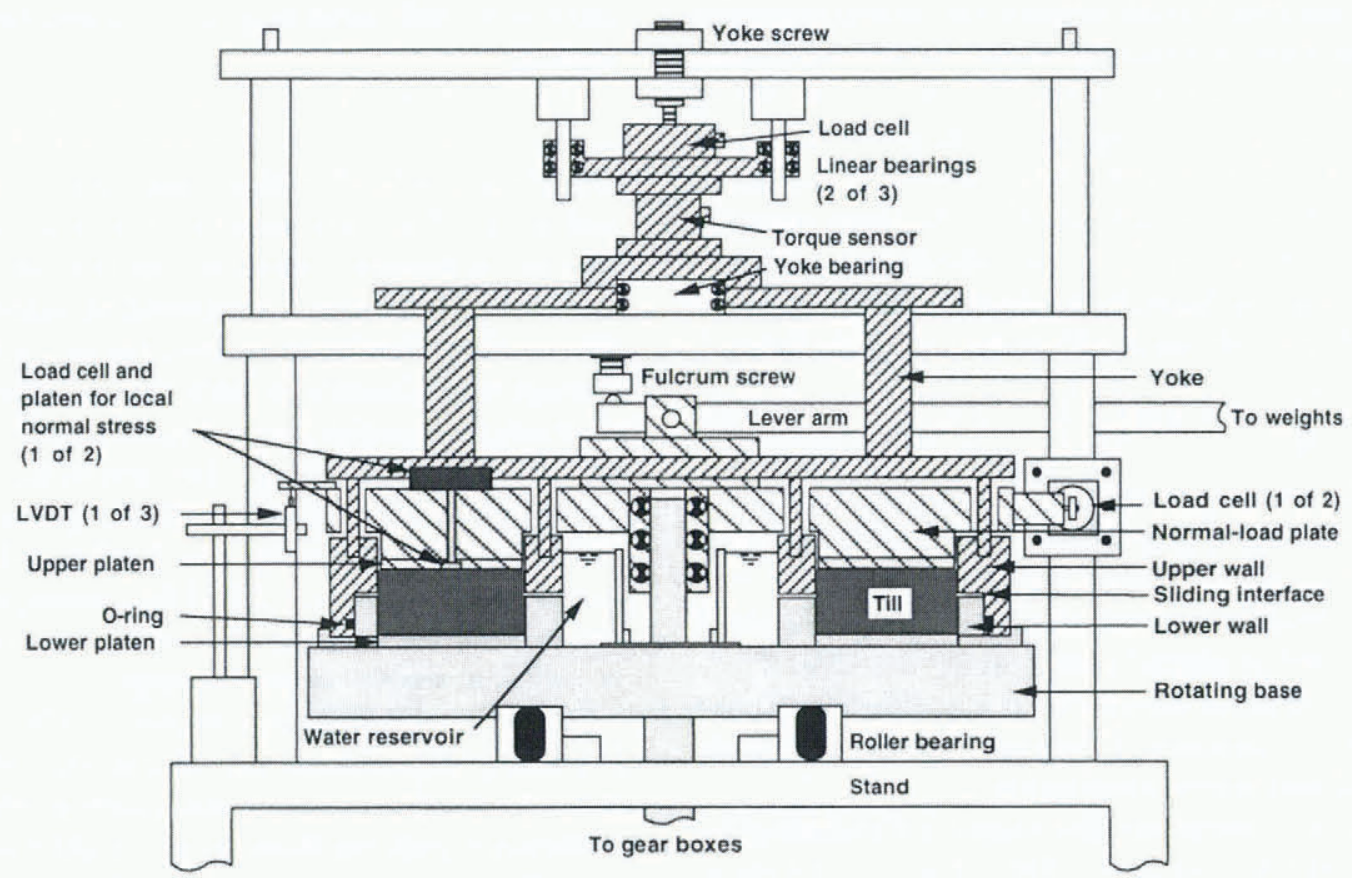

\section{Sample chamber}

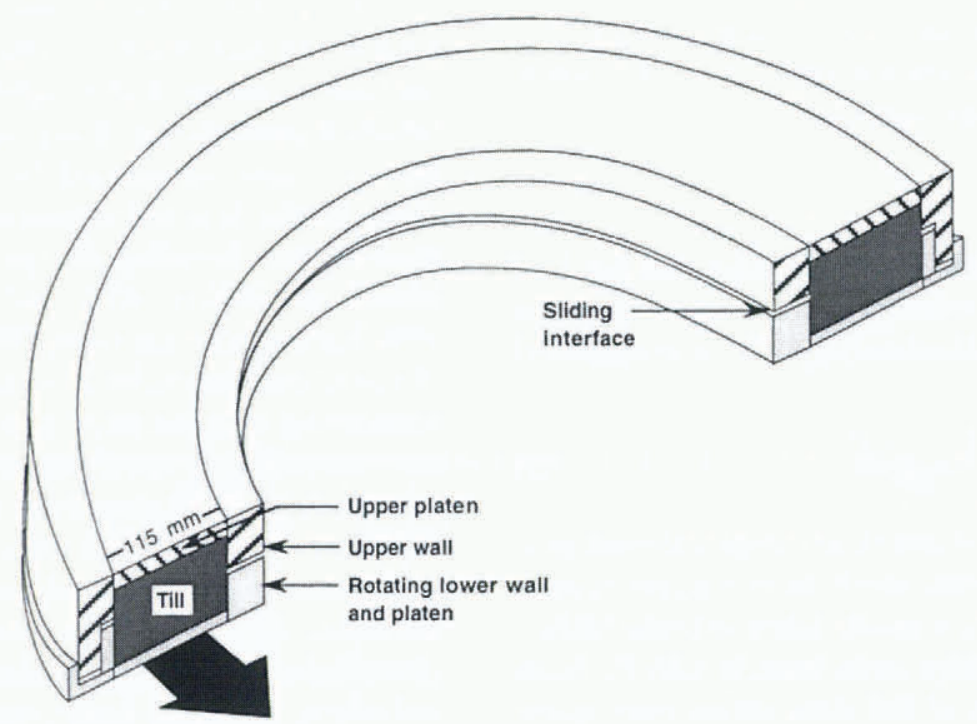

Fig. 1. Line drawing of the ring-shear device and a close-up of the sample chamber. Lightly shaded components rotate. In the upper drawing, the gearboxes, electric motor, and dead weights on the lever arm are not shown.

hydraulic communication with the till. Tests are therefore "drained", in the vernacular of geotechnical testing.

The specimen is sheared by rotating the platen in contact with the base of the specimen at a controlled rate with a variable-speed electric motor and gearboxes. The normalload plate (Fig. 1) that grips the top of the specimen is kept from rotating by two diametrically positioned roller platens that extend from the perimeter of the plate and press on load cells. These load cells measure the resistance to shearing. The lower walls adjacent to the specimen move with the rotating base; the upper walls are fixed and held by an independent assembly called the yoke. Adjusting a screw at the top of the yoke either lifts the upper walls above the lower walls by a fraction of a millimeter forming a gap, or presses the upper walls against the lower walls. A torque sensor and a tension/compression load cell are mounted in the axis of the yoke and record the circumferential and vertical frictional forces on the upper walls that arise due to shearing and changes in volume of the specimen, respectively. These forces are factored into the data reduction (Iverson and others, 1997). In some tests, transparent outer walls made of hard-coated acrylic are used to allow the distribution of strain at the outer edge of the specimen to be observed continuously. 
A uniform stress normal to the shearing direction is applied by the normal-load plate (Fig. 1), which is loaded with dead weights hung on a lever arm. Local stresses on this plate are measured over two circular platens, 9 and $18 \mathrm{~mm}$ in diameter, that are mounted flush with the platen surface and connected to load cells. Data from these sensors have been discussed elsewhere (Iverson and others, 1996, 1997). The normal-load plate is free to move vertically as the specimen thickness changes during shearing. This thickness is recorded by three displacement transducers that press on tabs that extend from the perimeter of the normalload plate.

\section{PROCEDURE}

Till is added to the sample chamber as a disaggregated, water-saturated slurry. Clasts with diameters larger than one-tenth of the minimum dimension of the specimen, those greater than about $6 \mathrm{~mm}$ in diameter, are removed from the specimen, as is the convention in soil testing (Head, 1989, p. 83). The sediment is leveled to a uniform thickness of 65-75 mm. Columns of displacement markers, a few $\mathrm{mm}$ in diameter and consisting of either segmented aluminum rods or spherical wooden beads, are injected vertically into the till at several positions across the width of the specimen.

The water reservoir is then filled, the normal-load plate is added, and the yoke is assembled. The normal stress is then increased incrementally, each increment causing consolidation and associated flow of water from the specimen to the reservoir (Iverson and others, 1997). Once the full load is applied to the normal-load plate and consolidation has essentially stopped, the yoke is adjusted so that the upper walls press gently against the lower walls to inhibit the intrusion of sediment along the sliding interface. A thin layer of vacuum grease is applied there before an experiment to minimize friction. The motor that drives the rotating base is then turned on, and the specimen begins to shear.

In some experiments, the displacement rate of the base was held constant at a low value, $18 \mathrm{~m} \mathrm{a}^{-1}$ at the specimen center line, and the stress normal to the shearing direction was varied. The initial normal stress during shearing was the largest applied, $145 \mathrm{kPa}$. This was to insure that the teeth on the upper platen had fully engaged the specimen when shearing commenced. Shearing was continued at that normal stress until the shear stress and specimen thickness became essentially steady. The normal stress was then decreased to a lower value and kept there until the ultimate (steady) strength was again attained. This procedure was repeated six times. Then the stress was stepped up three times to determine if the sign of the stress increments affected the results.

In other experiments, the effect of the rate of shearing displacement on the ultimate strength of the till was studied. The applied normal stress was kept steady at $85 \mathrm{kPa}$, and shearing rates were stepped up from 18 to $810 \mathrm{~m} \mathrm{a}^{-1}$ and then down again. At each shearing rate, the deformation was continued until the ultimate strength had been reached.

Note that it is not necessary to remold the specimen between test segments at a given normal stress or shearing rate. This is because the ultimate strength of the till and its critical-state porosity attained at a sufficiently large strain are independent of the strain history (e.g. Atkinson, 1993).

At the conclusion of each test, the yoke is disassembled, the normal-load plate is removed, and the positions of the displacement markers are measured during careful dissection of the specimen. These measurements invariably show that strain is not distributed uniformly across the full thickness of the specimen, but is focused in a zone that is centered at the elevation of the sliding interface between the upper and lower walls (Iverson and others, 1997). These measurements can be used to calculate the approximate shear-strain rate at the specimen center line associated with a given rate of shearing displacement.

Two tills have been studied with the device: a basal till collected from bencath the margin of Storglaciären in northern Sweden (Baker and Hooyer, 1996), and the Two Rivers till of the Lake Michigan Lobe, a part of the southern margin of the Laurentide ice sheet that may have deformed its bed (Clark, 1994). The Storglaciären till is a sandy loam (4\% clay, $21 \%$ silt and $75 \%$ sand and gravel). In contrast, the Two Rivers till is a clay loam $32 \%$ clay, $30 \%$ silt and $38 \%$ sand and gravel) that is conspicuously cohesive.

\section{RESULTS}

Stress-strain data from experiments with these tills have been presented previously (Iverson and others, 1997) and will be only summarized here. After shearing was initiated, the shear stress supported by the Storglaciären till increased monotonically to its ultimate value, as is the case with other clay-poor, normally consolidated sediments (e.g. Skempton, 1985). The Two Rivers till behaved similarly in some experiments, but in other experiments displayed a post-peak reduction in strength that is typical of clay-rich sediment, in which clay particles align during shearing, thereby reducing internal friction (Skempton, 1985). Some of the specimen $(<1 \%$ of the specimen volume) was squeezed into the sliding interface between the upper and lower walls, a chronic problem in ring-shear tests (Bishop and others, 1971; Tika and others, 1996). Thus, some of the specimen was lost from the sample chamber, particularly in tests on the Two Rivers till. This precluded the possibility of detecting small changes in the porosity of the specimens. However, as first argued by Bishop and others (1971), such small sediment losses are not expected to compromise the quality of the other stressstrain data. In particular, it is worth noting that the reactive force on the normal-load plate that is used to compute the shear stress is independent of the friction between the upper and lower walls that may arise due to sediment intrusion along the sliding interface. This is because the normal-load plate and walls are not coupled.

Results of test segments at different normal stresses are shown in Figure 2. Tests on both tills indicate an approximately linear relation between ultimate strength and normal stress, with best fits yielding Coulomb relations of the form: $\tau_{\mathrm{u}}=c_{\mathrm{i}}+P_{\mathrm{e}} \tan \phi_{\mathrm{u}}$, where $c_{\mathrm{i}}$ is the cohesion intercept (Lambe and Whitman, 1979, p. 308) and the normal stress is equated with $P_{\mathrm{e}}$, a reasonable first assumption since the tests were drained and carried out to high strains. The ultimate friction angle of the Two Rivers till, $17.8^{\circ}$, is significantly smaller than that of the Storglaciären till, 26.3. This is expected, owing to the larger clay content of the Two Rivers till. Indeed, these values are broadly consistent with published values of $\phi_{11}$ as a function of clay fraction Lambe and Whitman, 1979, p. 313). Cohesion intercepts of 5 and 


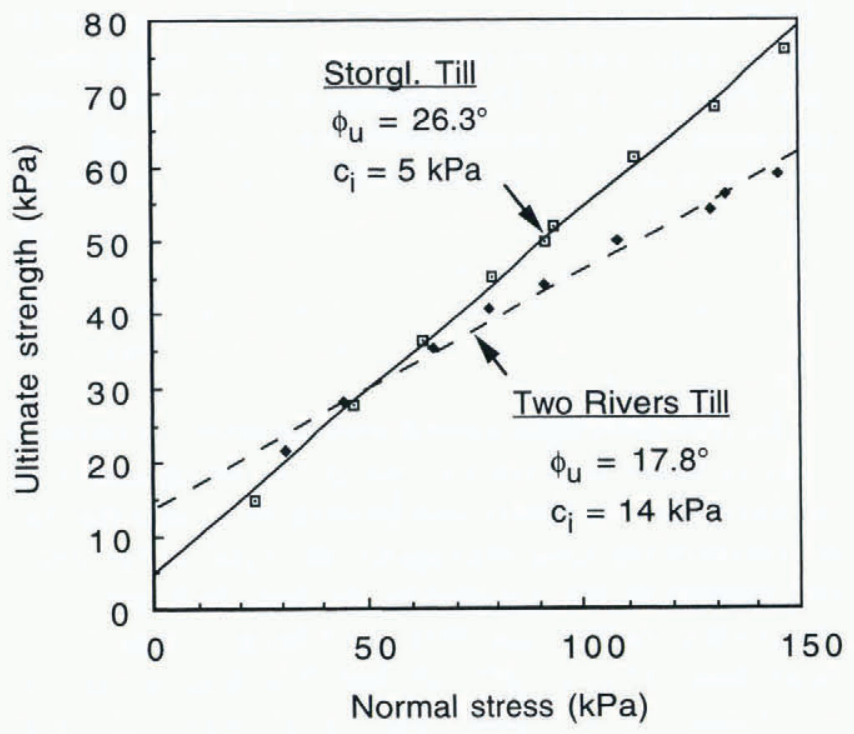

Fig. 2. Ultimate strength of the Storglaciären and Two Rivers tills as a function of normal stress. The parameters $\phi_{\mathrm{u}}$ and $c_{\mathrm{i}}$ are the ultimate friction angle and cohesion intercept, respectively.

$14 \mathrm{kPa}$ for the Storglaciären and Two Rivers tills, respectively, are indicated. As noted earlier, true cohesion, in principle, is absent in the critical state and, in fact, both datasets diverge slightly from the linear fit by trending more nearly toward the origin at small normal stresses. A reasonable assumption is that if sufficiently small normal stresses could have been applied in these tests, the line defined by the data would have curved to pass through the origin, which is a common finding in such tests (Lambe and Whitman, 1979, p. 139). True cohesion is therefore probably zero, and $\phi_{\mathrm{u}}$ depends weakly on the magnitude of the normal stress.

Results of test segments at different rates of shearing displacement are shown in Figure 3. These results indicate that over nearly the full glacial range of shearing rates, there was little variation in the ultimate strength of the two tills. This is consistent with a plastic rheology. There was a slight tendency for both tills to weaken as the shearing rate was increased, corresponding to negative values of $b$ and $n$ in Equations (1) and (2), respectively. Such behavior is sometimes called velocity weakening by geophysicists (e.g. Biegel and others, 1989). Values of $b$ of -0.015 and -0.010 are indicated for the Storglaciären and Two Rivers tills, respectively.

\section{DISCUSSION}

These results motivate two important questions. (1) Is the slight velocity weakening observed reasonable, when viewed within the context of other such experimental work on similar materials? (2) Are the results consistent with the distributed shear strain that has sometimes been observed in subglacial till?

\section{Velocity weakening}

To address the first question, we turn to extensive data compiled by Tika and others (1996, table 3 and fig. 37) from ringshear tests on a variety of materials. These data indicate that velocity weakening by as much as $10 \%$ over the range of shearing rates in our study may occur in fine-grained sediment, including till. The sediment most susceptible to this

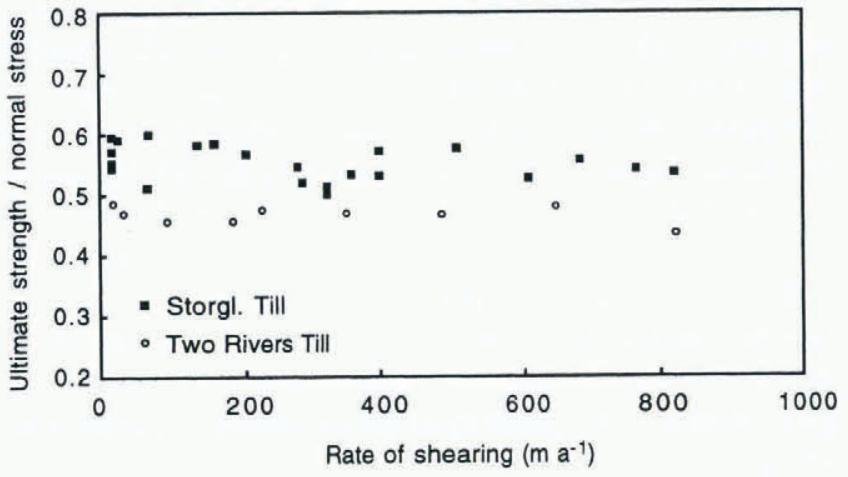

Fig. 3. The ratio of ultimate strength to normal stress in the Storglaciären and Two Rivers tills as a function of shearing rate. Shear strain was non-uniformly distributed across the specimen thickness, but measurements indicate that most strain was focused in zones approximately 35 and $10 \mathrm{~mm}$ thick for the Storglaciären and Two Rivers tills, respectively (Iverson and others, 1997). Thus, the approximate ranges over which shear-strain rates were varied for the two tills were $0.54-23 \times 10^{3}$ and $1.8-81 \times 10^{3} a^{-1}$, respectively. The shear-zone thickness was independent of shearing rate, as indicated by tests in which the shearing rate was changed by a factor of two with no systematic effect on the shear-strain distribution.

effect contained clay but also contained various amounts of silt and sometimes sand. Relatively pure clays, in contrast, showed a tendency for slight increases in ultimate strength with increasing shearing rate, consistent with data from other tests on clays (Mitchell, 1993, p. 343).

Following the explanation provided by Tika and others, we suggest that the slight velocity weakening observed in our tests resulted from slightly larger critical-state porosities at higher shearing rates. This would reduce the degree of grain interlocking, and thereby the ultimate friction angle. Clay and silt that contained significant concentrations of coarser particles might be most susceptible to this effect, because the extent of dilation induced by increases in strain rate might scale with the concentration of large grains. Unfortunately, this hypothesis cannot be tested with the available records of specimen thickness because, as noted earlier, a small but significant fraction of the specimen was lost from the sample chamber during shearing, obscuring small porosity differences. This problem has recently been corrected with newly designed walls, so future tests may clarify this issue.

Distributed shear strain in Coulomb-plastic till: dilatant hardening

Although the results of these tests indicate that the ultimate strength of till is decreased slightly as its shear-strain rate increases, the effect is small. Thus, these results support the idealization that till is a Coulomb-plastic material. As discussed earlier, the theory of non-associated plasticity, distinct-element modelling and laboratory experiments indicate that strain in granular materials tends to localize in discrete bands. The slight velocity weakening observed reinforces this conclusion because as the rate of displacement across a shear band increases, the band should weaken further and therefore continue to focus strain. These results, therefore, seem to be contradicted by the distributed defor- 
mation that has sometimes been observed in till beneath glaciers.

One possible explanation is that our rheological results are not applicable because tests should have been carried out at constant shear stresses (e.g. Ho and others, 1996), rather than at constant strain rates. Only the latter, at present, are possible with our device. We are aware of no devices that are capable both of stress-controlled tests and of inducing the large shear strains essential to reach the ultimate strength of fine-grained sediment. It is not difficult to argue that transient stress-strain behavior, prior to reaching the critical state, should be different for the two kinds of tests. In a stress-controlled test, the final, steady state of stress in the specimen is developed upon loading. In contrast, in a strain-rate controlled test, a steady stress state develops in the specimen only after it has been sheared to some finite strain. There is no obvious reason to believe, however, that the final stress state at high strains should be different in the two types of tests. Thus, although stress-controlled tests would be of interest, we are skeptical that they would yield a relation between ultimate strength and shear-strain rate that is significantly different from that observed in this study.

A second possibility is that shear strain is distributed by grain bridges that develop in granular materials (e.g. Sammis and others, 1987; Hooke and Iverson, 1995; Iverson and others, 1996). Distinct-element model simulations demonstrate that for relatively equigranular sediment, such bridges form and do indeed distribute shear strain (Morgan and Boettcher, in press). However, these simulations also indicate that for grain-size distributions similar to those of till, bridges are suppressed due to the presence of fine particles. This was precisely the effect observed in comminution experiments with our ring-shear device in which grain bridging became dramatically subdued as a fine fraction developed (Iverson and others, 1996).

A third possible explanation, which will be the focus of the rest of this discussion, is that unsteady till deformation may contribute to distributed strain in glacier beds. It is reasonably well documented that water-pressure fluctuations beneath glaciers on soft beds cause the bed to deform in shear cyclically (Blake and others, 1992; Iverson and others, 1995; Fischer and Clarke, 1997; Hooke and others, 1997). As water pressure rises, the ice reduces its coupling with the bed, causing the till to relax elastically in shear up-glacier, just as rocks bounding a fault relax during a seismic event. As water pressure decreases, local shear stresses on the bed increase sufficiently to cause renewed permanent deformation down-glacier. Thus, shearing of till beneath glaciers that are subject to daily changes in water pressure is not steady but periodic.

During a deformation event, shear strain should tend to focus in thin bands within the till. These bands may be inclined Coulomb slip surfaces or oriented parallel to the bed, corresponding to the "Y-shears" that have been produced experimentally (e.g. Mandl and others, 1977; Logan and others, 1992; Beeler and others, 1996) and simulated numerically (Morgan and Boettcher, in press). Their position should be governed by mechanical heterogeneities in the till that give rise to small spatial variations in shear strength and by the state of stress, which should depend on the factors considered by Alley (1989) and on the direction and magnitude of groundwater flow through the till.

These bands should dilate upon shearing if the till is denser than in the critical state (e.g. Clarke, 1987). Such "overconsolidation" is expected because, in the absence of shearing, the cyclic effective normal stress associated with the fluctuating water pressure should cause net consolidation. It is well known that repeated cycles of compression and decompression cause a cumulative decrease in porosity (e.g. Jumikis, 1962, p.367; Clarke, 1987), sometimes termed "ratcheting". Thus, till that has not been sheared for a time but that has been subject to fluctuating effective normal stress will likely be denser than that in the critical state, and should therefore dilate upon shearing.

Consider now the effect of a dilating shear band on the distribution of pore-water pressure in basal till. Assuming that the till is saturated with water, pore water will flow toward the opening void space within the band. If the rate of dilation is large relative to the rate of pore-water flow, there should be a reduction in pore-water pressure within the band that should strengthen it: an effect called dilatant hardening. This effect was described when dilation of granular materials was first recognized (Reynolds, 1885) and has been applied widely to strain partitioning in dilatant rock masses (Frank, 1965; Rice, 1975; Rudnicki, 1984; Rudnicki and Chen, 1988).

Strengthening of a shear band by dilatant hardening will cause the locus of strain to shift elsewhere in the sediment. A calculation illustrates that tills, owing to their low permeability, will be susceptible to this process, even at small rates of dilation. Consider a shear band in a much larger body of till that begins to undergo steady relative motion across its thickness at a rate, $V_{\mathrm{r}}$ (Fig. 4). The band will dilate during the early stages of shearing. A reasonable idealization is that the consequent vertical strain, $\epsilon_{\mathrm{v}}$, is linearly proportional to the shear strain $\gamma$, such that $\epsilon_{\mathrm{v}}=C \gamma$. It then follows that the dilation rate, the rate of increase in the thickness of the shear band, is $C V_{\mathrm{r}}$. Continuity requires that the volumetric specific discharge of water into the shear band from the adjacent till, $q$, equals the dilation rate. Thus,

$$
q=C V_{\mathrm{r}} \text {. }
$$

Eventually the till reaches the critical state, in which there is no further dilation with shearing. The time required to reach the critical state, $t_{\mathrm{c}}$, can be written in terms of the total vertical strain associated with dilation of the band, $\epsilon_{\mathrm{t}}$ :

$$
t_{\mathrm{c}}=\frac{\epsilon_{\mathrm{t}} T_{\mathrm{i}}}{C V_{\mathrm{r}}},
$$

where $T_{\mathrm{i}}$ is the initial thickness of the shear band. The value of $\epsilon_{\mathrm{t}}$ depends on the effective stress normal to the shear band, the initial porosity of the sediment, and the sediment composition.

Solving for the pore-pressure deficit in the shear band during deformation is mathematically analogous to the

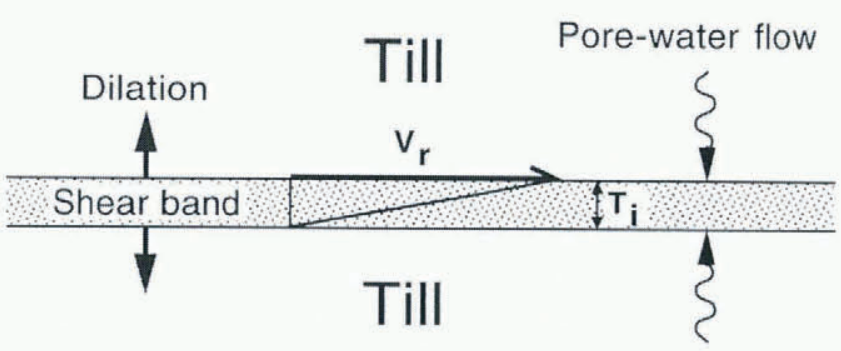

Fig. 4. A thin band shearing and dilating within an infinite thickness of water-saturated sediment. 
problem of determining the temperature in a thin heat sink that is turned on and then off within a one-dimensional infinite solid that is initially at a uniform temperature. The solution to this diffusion problem yields the pore-pressure deficit in the shear band, $u_{\mathrm{d}}$, as a function of time, $t$ :

$$
\begin{aligned}
& u_{\mathrm{d}}=\frac{\rho_{\mathrm{w}} g q}{K} \sqrt{\frac{\kappa t}{\pi}} \quad 0<t<t_{\mathrm{c}} \\
& u_{\mathrm{d}}=\frac{0.56 \rho_{\mathrm{w}} g q \sqrt{\kappa}}{K}\left(\sqrt{t}-\sqrt{t-t_{\mathrm{c}}}\right) \quad t>t_{\mathrm{c}}
\end{aligned}
$$

(Carslaw and Jaeger, 1959, p. 77), where $\rho_{\mathrm{W}}$ is the density of water, and $K$ is the hydraulic conductivity of the till. The hydraulic diffusivity, $\kappa$, depends on $K$ and on the compressibility of the till, $\alpha$, and pore water, $\beta$ :

$$
\kappa=\frac{K}{\rho_{\mathrm{w}} g(\alpha+\eta \beta)}
$$

where $\eta$ is the till porosity (Freeze and Cherry, 1979). Substituting Equations (3), (4) and (6) into Equations (5) yields $u_{\mathrm{d}}$ as a function of $t, V_{\mathrm{r}}, \epsilon_{\mathrm{t}}, T_{\mathrm{i}}$ and the hydraulic and material properties of the till-water mixture:

$$
\begin{gathered}
u_{\mathrm{d}}=C V_{\mathrm{r}} \sqrt{\frac{\rho_{\mathrm{w}} g t}{K \pi(\alpha+n \beta)}} \quad 0<t<\epsilon_{\mathrm{t}} T_{\mathrm{i}} / C V_{\mathrm{r}} \\
u_{\mathrm{d}}=0.56 C V_{\mathrm{r}} \sqrt{\frac{\rho_{\mathrm{w}} g}{K(\alpha+n \beta)}}\left(\sqrt{t}-\sqrt{t-\frac{\epsilon_{\mathrm{t}} T_{\mathrm{i}}}{C V_{\mathrm{r}}}}\right) \\
t>\epsilon_{\mathrm{t}} T_{\mathrm{i}} / C V_{\mathrm{r}} .
\end{gathered}
$$

Let us now make a conservative estimate of $u_{\mathrm{d}}$ and consequent dilatant hardening. To do this, we choose a small value for the shearing velocity, $V_{\mathrm{r}}=0.1 \mathrm{~m} \mathrm{~d}^{-1}$, and a small strain due to dilation, $\epsilon_{\mathrm{t}}=0.02$ (Fig. 5a). Depending upon the extent of consolidation, strains due to dilation may sometimes exceed 0.10 (e.g. Lambe and Whitman, 1979, p. 131). The thickness of the shear band is assumed to be $20 \mathrm{~mm}$. Other parameter values are discussed in the figure caption. There will be a significant reduction in pore-water pressure within the band that is largest when the band stops dilating (Fig. 5b). The effect is greater in the Two Rivers till, due to its lower permeability, but even in the clay-poor Storglaciären till an $8 \mathrm{kPa}$ reduction in pore pressure is expected. The shear strength of the band in excess of that under equilibrium conditions, $\tau_{\mathrm{e}}$, is given by the Coulomb criterion: $\tau_{\mathrm{e}}=u_{\mathrm{d}} \tan \phi$, where $u_{\mathrm{d}}$ is the pore-pressure deficit in the shear band, and $\phi$ is the friction angle. Taking into consideration the maximum decrease in friction angle expected with dilation (Fig. 5c), the shear strength of the band is nevertheless increased by about 5 and $17 \mathrm{kPa}$ for the Storglaciären and Two Rivers tills, respectively, as a consequence of shearing and associated dilatant hardening (Fig. 5d). Two days after dilation stops, the band in the Two Rivers till is still strengthened by more than $1 \mathrm{kPa}$.

Figure 5 illustrates an important aspect of dilatant hardening in granular materials: it cannot persist during steady deformation because dilation occurs only transiently, during the early stages of deformation. It is therefore not a viable hypothesis for distributing strain in till undergoing critical-state deformation.

Consider, however, the aforementioned cyclic deformation of till that arises due to water-pressure fluctuations beneath temperate glaciers. During the periods between shearing episodes, dilatant zones will no longer be shearing and, due to their pore-pressure deficit, will begin consolidat-
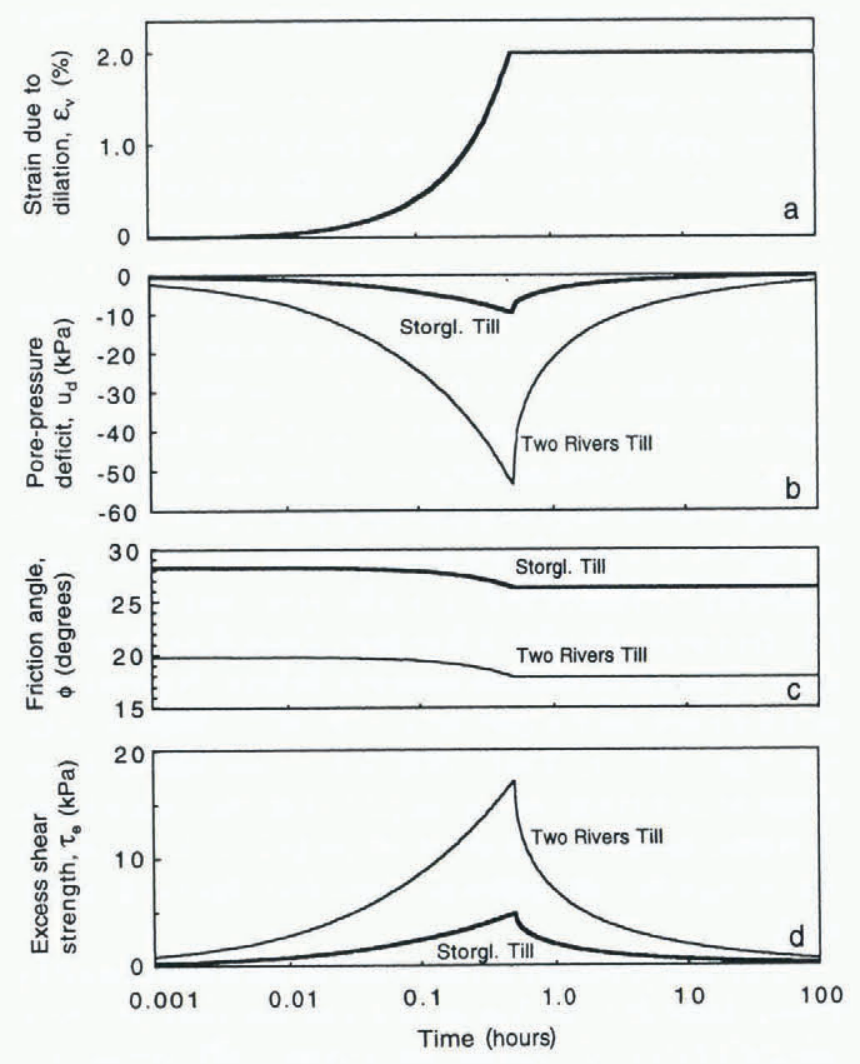

Fig. 5. Idealized dilation of a shear band and consequent changes in its pore pressure, friction angle and shear strength. Changes in pore pressure are calculated using Equations (7). Assumed changes in friction angle with dilation are based on data in Lambe and Whitman $(1979$, ch. 11). For the Storglaciären till, $K=10^{-8} \mathrm{~m} \mathrm{~s}^{-1}$ and $\alpha=3 \times 10^{-7} \mathrm{~Pa}^{-1}$ (Fischer and others, in press). Values for the Two Rivers till are not as well known, but both parameters can be estimated from the till diffusivity, which has been determined in consolidation tests (Iverson and others, 1997): $K=10^{10} \mathrm{~m} \mathrm{~s}^{-1}$ and $\alpha=10^{-6} \mathrm{~Pa}^{-1}$ are reasonable values. $A$ good value for $C$ is 0.2 (Lambe and Whitman, 1979, ch. 10). The initial porosity assumed is 0.3 and $\beta=4 \times 10^{-10} \mathrm{~Pa}$.

ing back to the ambient porosity of the till. Each shearing episode will therefore cause renewed dilation, regardless of the total shear strain that the till has experienced. The consequent dilatant hardening should cause the locus of strain to shift elsewhere. An alternative would be that the shear band thickens, but that is unlikely since the pore-pressure deficit in the band draws down the pore pressure in adjacent zones, strengthening them also (Carslaw and Jaeger, 1959, p. 75, equation 7). Thus, under transient loading and deformation, strain is expected to occur at different successive locations, a process that when integrated over time should yield a distributed displacement field.

This hypothesis provides one possible means of reconciling our experimental results with distributed shear strain that has sometimes been recorded in till beneath glaciers. It is consistent with the observation that significant motion at depth in glacier beds has, to date, been documented beneath only glaciers subject to periodic changes in water pressure (Boulton and Hindmarsh, 1987; Blake and others, 1992; Iverson and others, 1995). However, in no way does this hypothesis preclude other factors that may help distribute shear strain, such as deformation of till around large clasts (e.g. Tulaczyk, in press). 


\section{CONCLUSIONS}

The results of these experiments indicate that the ultimate strength of till increases linearly with effective pressure and decreases slightly with deformation rate. The latter effect may be due to a small increase in critical-state porosity with shear-strain rate, although such small porosity differences could not be detected in these experiments. Owing to the small influence of deformation rate on the till strength, a reasonable idealization is that till is a Coulomb-plastic material.

These results are not contradicted by the distributed shear strain that has sometimes been observed in subglacial till. Dilatant hardening may distribute strain in glacier beds that are subject to water-pressure fluctuations, cyclic deformation and attendant cycles of dilation and consolidation. Tills, as a result of their low permeability, should be susceptible to this process.

\section{ACKNOWLEDGEMENTS}

We thankJ. Marchetti, foreman of the electrical engineering machine shop at the University of Minnesota, for his skillful assistance in constructing the ring-shear device. R. LeB. Hooke and an anonymous reviewer provided helpful criticism of the manuscript. We also thank P. U. Clark for providing us with a large sample of the Two Rivers till. This work was supported by U.S. National Science Foundation grants OPP-9224209 and OPP-9530814.

\section{REFERENCES}

Alley, R. B. 1989. Water-pressure coupling of sliding and bed deformation: II. Velocity-depth profiles. 7. Glaciol., 35 119). 119-129.

Alley, R. B. 1991. Deforming-bed origin for southern Laurentide till sheets? f. Glaciol., 37 (125), 67-76.

Alley, R. B. 1992. How can low-pressure channels and deforming tills coexist subglacially? f. Glaciol., 38 (128), $200-207$.

Alley, R. B., D. D. Blankenship, C. R. Bentley and S. T. Rooney. 1986. Deformation of till beneath Ice Stream B, West Antarctica. Nature, 3226074 $57-59$.

Atkinson, J. H. 1993. An introduction to the mechanics of soils and foundations through critical stale soil mechanics. London, McGraw-Hill.

Baker, R.W. and T. S. Hooyer. 1996. Multiple till layers beneath Storglaciären. Slockholms Universitet. Naturgeografiska Institutionen. Forskningsrapport $103,25-29$.

Beeler, N. M., T. E. Tullis, M. L. Blanpied and J. D. Weeks. 1996. Frictional behaviour of large displacement experimental faults. 7. Geophys. Res. 101 (B4), $8697-8715$.

Biegel, R. L., C. G. Sammis and J. Dieterich. 1989. The frictional properties of simulated gouge having a fractal particle size distribution. 7 . Strucl. Geol., 11 7), 827-846.

Bishop, A. W., G. E. Green, V. K. Garga, A. Andersen and J. D. Brown. 1971. A new ring shear apparatus and its application to the measurement of residual strength. Géotechnique, 21 (4), 273-328.

Blake, E., G. K. C. Clarke and M. C. Gérin. 1992. Tools for examining subglacial bed deformation. J. Glaciol., 38 (130), 388-396.

Blankenship, D. D., C. R. Bentley, S. T. Rooney and R. B. Alley. 1986. Seismic measurements reveal a saturated porous layer beneath an active Antarctic ice stream. Vature, 322 6074, 54-57.

Boulton, G. S. 1996. The origin of till sequences by subglacial sediment deformation beneath mid-latitude ice sheets. Ann. Glaciol., 22. 75-84.

Boulton, G.S. and R.C.A. Hindmarsh. 1987. Sediment deformation beneath glaciers: rheology and geological consequences. .7. Geophys. Res., 92 B9), 90599082.

Brown, N. E., B. Hallet and D. B. Booth. 1987. Rapid soft bed sliding of the Puget glacial lobe. J. Geophys. Res., 92 (B9), 89858997.

Carslaw, H. S. and J. C. Jaeger. 1959. Conduction of heat in solids. Second edition. Oxford, Clarendon Press.

Clark, P. U. 1994. Unstable behavior of the Laurentide ice sheet over deforming sediment and its implications for climate change. Quat. Res.,
$41(1), 19-25$.

Clarke, G. K. C. 1987. Subglacial till: a physical framework for its properties and processes. 7. Geophys. Res., 92 (B9), 9023-9036.

Cundall, P. A. and O. D. L. Strack. 1979. A discrete numerical model for granular assemblies. Géotechnique, 29 (1), 47-65.

Dewhurst, D. N., M. B. Clennell, K. M. Brown and G. K. Westbrook. 1996. Fabric and hydraulic conductivity of sheared clays. Géotechnique, 46 (4), $761-768$.

Fischer, U. H. and G. K. C. Clarke. 1994. Ploughing of subglacial sediment. 7. Glaciol., 40 (134), 97-106.

Fischer, U. H. and G. K. C. Clarke. 1997. Stick-slip sliding behaviour at the base of a glacier. Ann. Glaciol., 24,390-396.

Fischer, U. H., N. R. Iverson, B. Hanson, R. LeB. Hooke and P. Jansson. In press. Estimation of hydraulic properties of subglacial till from ploughmeter measurements. J. Glaciol.

Frank, F. C. 1965. On dilatancy in relation to seismic sources. Rev. Geophys. Space Phys, 3, 485-503.

Freeze, R. A. and J. A. Cherry. 1979. Groundwater. Englewood Cliffs, NJ, Prentice-Hall.

Gerbault, M., A. N. B. Polakov and M. Daignieres. 1998. Prediction of faulting from theories of elasticity and plasticity: what are the limits? Struct. Geol., 20 2-3), 301-320.

Head, K. H. 1989. Soil technician's handbook. New York, etc., John Wiley and Sons.

Ho, C. L., J. C. Vela, J.W. Jenson and P. U. Clark. 1996. Evaluation of longterm time-rate parameters of subglacial till. In Sheahan, T. C. and V. N. Kaliakin, eds. Measuring and modeling time dependent soil behavior. New York, American Society of Civil Engineers, 122 136. (ASCE Special Publication 61.

Hooke, R. LeB. and A. Elverhoi. 1996. Sediment flux from a fjord during glacial periods, Isfjorden, Spitsbergen. Global and Planetary Change, $12(1-4), 237-249$.

Hooke, R. LeB. and N. R. Iverson. 1995. Grain-size distribution in deforming subglacial tills: role of grain fracture. Geology, $23(1), 57-60$.

Hooke, R. LeB., B. Hanson, N. R. Iverson, P. Jansson and U. H. Fischer. 1997. Rheology of till beneath Storglaciären, Sweden. 7. Glaciol. $43(143), 172-179$.

Humphrey, N., B. Kamb, M. Fahnestock and H. Engelhardt. 1993. Characteristics of the bed of the lower Columbia Glacier, Alaska. J. Geophys. Res., $98(\mathrm{Bl}), 837-846$

Iverson, N. R., P. Jansson and R. LeB. Hooke. 1994. In-situ measurement of the strength of deforming subglacial till. .7. Glaciol., 40 136), 497-503.

Iverson, N. R., B. Hanson, R. LeB. Hooke and P. Jansson. 1995. Flow mechanism of glaciers on soft beds. Science, 267 (5194), 80-81.

Iverson, N.R., T. S. Hooyer and R. LeB. Hooke. 1996. A laboratory study of sediment deformation: stress heterogeneity and grain-size evolution. Ann. Glaciol., 22, 167-175.

Iverson, N. R., R.W. Baker and T. S. Hooyer. 1997. A ring-shear device for the study of till deformation: tests on tills with contrasting clay contents. Quat. Sci. Rev., 16 9), 1057-1066.

Iverson, R. M. 1986. Unsteady, nonuniform landslide motion: theoretical dynamics and the steady datum state. J. Geol., 94, 1-15.

Jenson, J. W., D. R. Mac Ayeal, P. U. Clark, C. L. Ho andJ. C. Vela. 1996. Numerical modeling of subglacial sediment deformation: implications for the behavior of the Lake Michigan Lobe, Laurentide ice sheet. J. Geophys. Res., 101 B4, 8717-8728.

Jumikis, A. R. 1962. Soil mechanics. Princeton, NJ, D. Van Nostrand.

Kamb, B. 1991. Rheological nonlinearity and flow instability in the deforming bed mechanism of ice stream motion. \%. Geophys. Res., 96 (B10), $16,585-16,595$.

Lambe, T.W. and R.V. Whitman. 1979. Soil mechanics, New York, etc., John Wiley and Sons.

Logan, J. M., C. A. Dengo, N. G. Higgs and Z. Z.. Wang, 1992. Fabrics of experimental fault zones: their development and relationship to mechanical behaviour. In Evans, B. and T. -F. Wong, eds. Fault mechanics and transport properties of rocks. London, Academic Press, 33-67.

MacAyeal, D. R. 1989. Large-scale ice flow over a viscous basal sediment: theory and application to Ice Stream B, Antarctica. 7. Geophys. Res. 94 (B4), 4071-4087.

MacAyeal, D. R. 1992. Irregular oscillations of the West Antarctic ice sheet. Nature, 359 (6390), 29-32.

Mandl, G., L. N.J. de Jong and A. Maltha. 1977. Shear zones in granular material an experimental study of their structure and mechanical genesis. Rock Mech., 9, $95-144$.

Mitchell, J. K. 1993. Fundamentals of soil behaviour. Second edition. New York, John Wiley and Sons Inc.

Morgan, J. K. and M. S. Boettcher. In press. Numerical simulations of granular shear zones using the distinct element method. I. Shear zone kinematics and micromechanics of localization. J. Geophys. Res. 
Reynolds, O. 1885. On the dilatancy of media composed of rigid particles in contact, with experimental illustrations. Philos. Mag., 20, 469-481.

Rice, J. R. 1975. On the stability of dilatant hardening for saturated rock masses. J. Geophys. Res., 80(11), 1531-1536.

Rudnicki, J.W. 1984. Effects of dilatant hardening on the development of concentrated shear deformation in fissured rock masses. F. Geophys. Res., 89 (B11), 9259-9270.

Rudnicki, J.W. and C. -H. Chen. 1988. Stabilization of rapid frictional slip on a weakening fault by dilatant hardening. 7. Geophys. Res., 93 (B5), $4745-4757$.

Sammis, C., G. King and R. Biegel. 1987. The kinematics of gouge deformation. Pure Appl. Geophys., 125 (5), 777-812.

Savage, W. Z. and A. F. Cheleborad. 1982. A model for creeping flow in landslides. Bull. Assoc. Eng. Geol., 19, 333-338.

Skempton, A.W. 1985. Residual strength of clays in landslides, folded strata, and the laboratory. Géotechnique, 35 (1), 3-18.
Tika, T. E., P. R. Vaughan and L. J. Lemos. 1996. Fast shearing of pre-existing shear zones in soil. Géotechnique, 46, 197-233.

Tulaczyk, S. In press. Ice sliding over weak, fine-grained tills: dependence of ice-till interactions on till granulometry. In Mickelson, D. M. andJ. V. Attig, eds. Glacial proceses: past and modern. Boulder, CO, Geological Society of America.

Vardoulakis, I. 1980. Shear band inclination and shear modulus of sand in biaxial tests. Int. F. Numer. Anal. Methods Geomech., 4, 103-119.

Vardoulakis, I. and B. Graf. 1985. Calibration of constitutive models for granular materials using data from biaxial experiments. Géotechnique, $35,299-317$

Vela, J. C. 1994. Rheological testing of subglacial till material. (M.Sc. thesis, Washington State University.)

Walder, J. S. and A. Fowler. 1994. Channelized subglacial drainage over a deformable bed. 7. Glaciol., 40 (134), 3-15.

MS received 7 January 1998 and accepled in revised form 9 June 1998 